\title{
Modeling shortwave solar radiation using the JGrass-NewAge system
}

\author{
G. Formetta ${ }^{1}$, R. Rigon ${ }^{1}$, J. L. Chávez ${ }^{2}$, and O. David ${ }^{2}$ \\ ${ }^{1}$ University of Trento, 77 Mesiano St., 38123 Trento, Italy \\ ${ }^{2}$ Dept. of Civil and Environmental Engineering, Colorado State University, Fort Collins, CO, USA
}

Correspondence to: G. Formetta (formetta@ing.unitn.it)

Received: 23 October 2012 - Published in Geosci. Model Dev. Discuss.: 18 December 2012

Revised: 21 May 2013 - Accepted: 4 June 2013 - Published: 5 July 2013

\begin{abstract}
This paper presents two new modeling components based on the object modeling system v3 (OMS3) for the calculation of the shortwave incident radiation $\left(R_{\mathrm{sw}} \downarrow\right)$ on complex topography settings, and the implementation of several ancillary tools. The first component, NewAGE-SwRB, accounts for elevation slope, aspect, shadow of the sites, and uses suitable parameterization for obtaining the cloudless irradiance. A second component, NewAGE-DEC-MOD's is implemented to estimate the irradiance reduction due to the presence of clouds according to three parameterizations. To obtain a working modeling composition that is comparable with ground data at measurement stations the two components are connected to a kriging component. With the help of an additional component, NewAGE-V (verification package), the performance of modeled $\left(R_{\mathrm{sw}} \downarrow\right)$ is quantitatively evaluated. The two components (and the various parameterizations they contain) are tested using the data from three basins, and some simple verification tests were carried out to assess the goodness of the methods used. Moreover, a raster mode test is performed in order to show the capability of the system in providing solar radiation raster maps. The components are part of a larger system, JGrass-NewAGE, their input and outputs are geometrical objects immediately displayed in a geographical information system (GIS). They can be used seamlessly with the various modeling solutions available in JGrass-NewAGE for the estimation of long wave radiation, evapotranspiration, and snow melting, as well as standalone components to just estimate shortwave radiation for various uses. The modularity of the approach leads to more accurate physical-statistical studies aimed to assess in depth
\end{abstract}

the components' performances and extends their results spatially, without the necessity of recoding any part of the component.

\section{Introduction}

Solar radiation at the top of the atmosphere is mainly function of Sun activity and the Sun-Earth distance. In the case of hydrological studies, the solar constant, $I_{\mathrm{sc}} \sim 1367\left[\mathrm{~W} \mathrm{~m}^{-2}\right.$ ], is defined at the mean Sun-Earth distance and used as a approximation of the irradiance at the top of the atmosphere. This value represents the maximum irradiance when the solar beam orthogonally hits Earth. Reduction of irradiance due to latitude and longitude, the day of the year, and the hour, is necessary, and can be easily calculated with the desired approximation, e.g., Iqbal (1983) and Liou (2002).

In the absence of clouds, solar radiation arrives at Earth's ground surface in two classes. Direct radiation $\left(S \downarrow^{*}\right)$ is that part of the solar beam that arrives at the surface without any interaction with Earth's atmosphere. Diffuse radiation $\left(d^{*} \downarrow\right)$ is shortwave radiation scattered downwards back to Earth's surface after hitting molecules of the atmospheric gases and aerosols. In this paper we will call the sum of $S \downarrow^{*}$ and $d^{*} \downarrow$, total shortwave radiation at the ground $\left(R_{\mathrm{Sw}} \downarrow\right)$.

When it is assumed that shortwave radiation hits rugged terrains, geometrical corrections can be applied to obtain the theoretical irradiances that hit the tilted terrain surface in absence of the atmosphere before accounting for the attenuations due to scattering. These quantities are therefore quite 
different from the actual radiation measured by instruments on the ground that account for the effects introduced by the atmosphere's scattering, reflections, and absorptions (Liou, 2002), and the landscape's multiple reflections, which will be denoted as $S \downarrow, d \downarrow$ and $R_{\mathrm{Sw}} \downarrow$ throughout the paper, and which shows an implementation of Corripio (2003) algorithms.

With the development of modern computing, power efficient methods were developed to estimate irradiance over vast mountain regions. Those studies were based on the elaboration of digital elevation models (DEMs) from which terrain characteristics were automatically derived and algorithms of various degrees of complexity were used. A long series of studies parameterize $R_{\mathrm{sw}} \downarrow$ since the $1960 \mathrm{~s}$, which are well reviewed in Duguay (1993). Among many, Dozier and Frew (1990) were the first to use DEMs for rapid estimation of $S \downarrow^{*}$ and $d^{*} \downarrow$ solar radiation; Dubayah (1994) presented a method that combines a simplified $d \downarrow$ radiation model with the topographic shading and the sky view field, and discussed various levels of complexities that can be introduced in the estimation of radiation beams. Ranzi and Rosso (1995) used Stokes' theorem to estimate $S \downarrow$ for a whole basin area; Gubler et al. (2012) tried to assess the inherent error in the estimation of the short wave incoming solar radiation. The above approaches were geared towards computational efficiency and simplified parameterizations, and produced several software packages that offer different methodologies, such as SolarFlus (in ArcInfo GIS) (Dubayah and Paul, 1995; Hetrick et al., 1993), Solar Analyst (Fu and Rich, 2000), SRAD (by Moore, 1992, and documented in Wilson and Gallant, 2000), Solei (Miklánek, 1993) or r.sun (Hofierka and Suri, 2002). They often integrate the models into GIS. Our modeling development embraces these previous efforts and is in line with those that emphasize the need to respond to the increased demand of modularity and interchangeability in hydrological and biophysical models that have been developed in the last decades. This trend is widespread in industrial software and gained momentum also in scientific research in environmental fields (e.g. Jones et al., 2001; David et al., 2002; Donatelli et al., 2006; Rizzoli et al., 2005).

Finally, our effort, in particular uses the object modeling system v.3.0 (OMS3) (David et al., 2002, 2010) components's framework and seamlessly integrates the Spatial Toolbox of the uDig GIS, which is based upon OMS3.

This paper introduces and tests model components for the estimation of the direct solar radiation that are part of a larger modeling effort called JGrass-NewAGE (Formetta et al., 2011, 2013) with the goal of estimating all the components of the hydrological cycle for medium to large catchments. Here shortwave radiation is an important part since it is necessary for estimating long wave radiation, evapotranspiration, and snow cover evolution. However, the modeling components developed in this study work also standalone, for any use outside of the original scope.

\section{The JGrass-NewAGE component for the estimation} of the shortwave radiation budget (NewAGE-SwRB)

This component, NewAGE-SwRB (or simply SwRB in the following), was developed to simulate the direct shortwave radiation budget in multiple points in a landscape, and to provide inputs to hydrological components independently of their geographical structure (either implementing fully distributed, semi-distributed, or lumped concepts). Hence, from a spatial point of view, the output of SwRB can be a raster (the results are provided for each pixel of the computational domain) or vector (the results are provided only in some points of the computational domain) according to the the modeler's needs, and in open GIS consortium standard formats (as GridCoverage and shapefiles, respectively). For the various uses, the component was re-implemented to provide results using a generic hourly, sub-hourly, and daily time step, according to the user's specifications.

While not trivial to obtain, the geometrical elaboration of the radiation that returns the incoming solar radiation on a tilted plane is given for granted, and it is estimated according to the elegant solution provided by Corripio's algorithms (Corripio, 2002, 2003).

\subsection{Direct solar radiation under cloudless sky conditions}

The incident $S \downarrow$ on an arbitrary sloping surface in a point under cloudless sky conditions is given by Corripio (2002):

$S \downarrow=C_{1} \cdot I_{\mathrm{sc}} \cdot E_{0} \cdot \cos \left(\theta_{\mathrm{s}}\right) \cdot\left(T_{\mathrm{s}}+\beta_{\mathrm{s}}\right) \cdot \psi$,

in which

$-C_{1}=0.9751$ is the fraction of solar radiation that is included between 0.3 and $3.0 \mu \mathrm{m}$ wavelengths;

- $E_{0}[-]$ is a correction factor related to Earth's orbit eccentricity computed according to Spencer (1971):

$$
\begin{aligned}
E_{0}= & 1.00011+0.034221 \cos (\kappa)+0.00128 \sin (\kappa) \\
& +0.000719 \cos (2 \kappa) \\
& +0.000077 \sin (2 \kappa) \\
& \kappa=2 \pi \cdot\left(\frac{N-1}{365}\right)
\end{aligned}
$$

where $\kappa$ is the day angle [rad] and $N$ is the day number of the year ( $N=1$ on 1 January, $N=365$ on 31 December);

- $T_{\mathrm{S}}[-]$, product of the atmospheric transmittances, is defined as

$T_{\mathrm{s}}=\tau_{\mathrm{r}} \cdot \tau_{0} \cdot \tau_{\mathrm{g}} \cdot \tau_{\mathrm{w}} \cdot \tau_{\mathrm{a}}$,

where the $\tau$ functions are the transmittance functions for Rayleigh scattering, ozone, uniformly mixed gases, 
Table 1. List of the SwRB component parameters used in simulations.

\begin{tabular}{|c|c|c|c|}
\hline Symbol & Parameter description & Dimension & Values \\
\hline$l_{\mathrm{oz}}$ & Vertical ozone layer thickness & [cm] & 0.30 \\
\hline V & Visibility, Corripio (2002) & {$[\mathrm{km}]$} & 80.0 \\
\hline$\omega_{0}$ & $\begin{array}{l}\text { Single-scattering albedo fraction } \\
\text { of incident energy scattered } \\
\text { to total attenuation by aerosols }\end{array}$ & {$[-]$} & 0.9 \\
\hline$F_{\mathrm{c}}$ & $\begin{array}{l}\text { Fraction of forward scattering to to- } \\
\text { tal scattering }\end{array}$ & {$[-]$} & 0.84 \\
\hline
\end{tabular}

water vapor, and aerosols, respectively. They are computed for each point as defined in the last part of this section;

- $\beta_{\mathrm{s}}[\mathrm{m}]$ is a correction factor for increased transmittance with elevation $z[\mathrm{~m}]$ defined according to Corripio (2002):

$\beta_{\mathrm{s}}= \begin{cases}2.2 \times 10^{-5} \cdot z_{\mathrm{p}} & \text { if } z \leq 3000 \mathrm{~m} \\ 2.2 \times 10^{-5} \cdot 3000.0 & \text { if } z>3000 \mathrm{~m}\end{cases}$

- $\theta_{\mathrm{S}}[\mathrm{rad}]$ is the angle between the Sun vector and the surface plane (Corripio, 2003); for a horizontal surface $\theta_{\mathrm{s}}=\theta_{\mathrm{z}}$ where $\theta_{\mathrm{z}}$ is the zenith angle;

- $\psi$ is the shadows index that accounts for the sun or shadow of the point under analysis, Eq. (6), and is modeled according to Corripio (2003). The algorithm computes a binary map (with a value of 0 the pixel is in the sun or 1 if the pixel is in the shadow) taking into account the surrounding topographic information and the solar position.

$$
\psi= \begin{cases}1 & \text { if the point } p \text { is in the sun } \\ 0 & \text { if the point } p \text { is in the shadow }\end{cases}
$$

The atmospheric transmittances in Eq. (4) are estimated according to Bird and Hulstrom (1981) and Iqbal (1983) to yield functions of the atmospheric pressure, the ozone layer thickness, the precipitable water amount, the zenith angle, and visibility, which are defined in this paper as fixed values, according to the literature values reported in Table 1 .

The transmittance function for Rayleigh scattering $\tau_{\mathrm{r}}[-]$ is estimated as

$\tau_{\mathrm{r}}=\exp \left[-0.0903 \cdot m_{\mathrm{a}}^{0.84} \cdot\left(1+m_{\mathrm{a}}-m_{\mathrm{a}}^{1.01}\right)\right]$,

where $m_{\mathrm{a}}[-]$ is the relative air mass at actual pressure defined as

$m_{\mathrm{a}}=m_{\mathrm{r}} \cdot\left(\frac{p}{1013.25}\right)$, in which $p$ [mbar] is the local atmospheric pressure, and $m_{\mathrm{r}}[-]$ relative optical air mass:

$m_{\mathrm{r}}=\frac{1.0}{\cos \left(\theta_{\mathrm{s}}\right)+0.15\left(93.885-(180 / 2 \pi) \theta_{\mathrm{s}}\right)^{-1.253}}$.

The transmittance by ozone $\tau_{\mathrm{o}}[-]$ is defined as:

$$
\begin{aligned}
\tau_{\mathrm{o}}= & 1.0-\left[0.1611 l_{\mathrm{oz}} m_{\mathrm{r}}\left(1.0+139.48 l_{\mathrm{oz}} m_{\mathrm{r}}\right)^{-0.3035}\right. \\
& \left.-\frac{0.002715 l_{\mathrm{oz}} m_{\mathrm{r}}}{1.0+0.044 l_{\mathrm{oz}} m_{\mathrm{r}}+0.0003\left(l_{\mathrm{oz}} m_{\mathrm{r}}\right)^{2}}\right]
\end{aligned}
$$

where $l_{\mathrm{oz}}[\mathrm{cm}]$ is the vertical ozone layer thickness, and the coefficients have the appropriate dimensionality to make $\tau_{0}$ dimensionless.

Transmittance by uniformly mixed gases $\tau_{\mathrm{g}}[-]$ is modeled as:

$\tau_{\mathrm{g}}=\exp \left[-0.0127 \cdot m_{\mathrm{a}}^{0.26}\right]$

Transmittance by water vapor $\tau_{\mathrm{w}}$ is estimated as

$\tau_{\mathrm{w}}=1.0-\frac{2.4959 w m_{\mathrm{r}}}{\left(1.0+79.034 w m_{\mathrm{r}}\right)^{0.6828}+6.385 w m_{\mathrm{r}}}$,

where $w[\mathrm{~cm}]$ is precipitable water in cm calculated according to Prata (1996). In this formulation $w$ depends on the atmospheric conditions of the point in which radiation is estimated and in particular $w$ is a function of air temperature and relative humidity.

Finally, the transmittance by aerosols $\tau_{\mathrm{a}}[-]$ is evaluated as

$\tau_{\mathrm{a}}=\left[0.97-1.265 \cdot V^{-0.66}\right]^{m_{\mathrm{a}}^{0.9}}$,

where $V[\mathrm{~km}]$ is the visibility, i.e., an estimation of the visibility extent as in Corripio (2002).

\subsection{Diffuse solar radiation under cloudless sky conditions}

The modeling of the diffuse component of solar radiation, $d \downarrow$, follows Iqbal (1983):

$d \downarrow=\left(d \downarrow_{\mathrm{r}}+d \downarrow_{\mathrm{a}}+d \downarrow_{\mathrm{m}}\right) \cdot V_{\mathrm{s}}$,

where $d \downarrow_{\mathrm{r}}, d \downarrow_{\mathrm{a}}$ and $d \downarrow_{\mathrm{m}}$ are the diffuse irradiance components after the first pass through the atmosphere due to the Rayleigh scattering, the aerosol scattering and multiple reflection, respectively.

The Rayleigh-scattered diffuse irradiance is computed as

$d \downarrow_{\mathrm{r}}=\frac{0.79 \cdot \cos \left(\theta_{\mathrm{z}}\right) \cdot I_{\mathrm{sc}} \cdot E_{0} \cdot \tau_{\mathrm{o}} \cdot \tau_{\mathrm{g}} \cdot \tau_{\mathrm{w}} \cdot \tau_{\mathrm{aa}} \cdot\left(1-\tau_{\mathrm{r}}\right)}{2.0 \cdot\left(1.0-m_{\mathrm{a}}+m_{\mathrm{a}}^{1.02}\right)}$,

where $\tau_{\text {aa }}$ is the transmittance of direct radiation due to aerosol absorbance modeled as

$\tau_{\mathrm{aa}}=1.0-\left(1-\omega_{0}\right) \cdot\left(1-m_{\mathrm{a}}+m_{\mathrm{a}}^{1.06}\right) \cdot\left(1.0-\tau_{\mathrm{a}}\right)$, 
where $\omega_{0}=0.9[-]$ is the single-scattering albedo fraction of incident energy scattered to total attenuation by aerosols (Hoyt, 1978).

The aerosol-scattered diffuse irradiance component is defined as

$$
\begin{aligned}
& d \downarrow_{\mathrm{a}}= \\
& \frac{0.79 \cdot I_{\mathrm{sc}} \cdot \cos \left(\theta_{\mathrm{z}}\right) \cdot E_{0} \cdot \tau_{\mathrm{o}} \cdot \tau_{\mathrm{g}} \cdot \tau_{\mathrm{w}} \cdot \tau_{\mathrm{aa}} \cdot F_{\mathrm{c}} \cdot\left(1-\tau_{\mathrm{as}}\right)}{1-m_{\mathrm{a}}+m_{\mathrm{a}}^{1.02}},
\end{aligned}
$$

where $\tau_{\mathrm{as}}=\tau_{\mathrm{a}} \tau_{\mathrm{aa}}^{-1}$ and $F_{\mathrm{c}}$ is the fraction of forward scattering to total scattering (Iqbal, 1983, $F_{\mathrm{c}}=0.84$ if no information about the aerosols are available).

The diffuse irradiance from multiple reflections between the earth and the atmosphere is computed as

$d \downarrow_{\mathrm{m}}=\frac{\left(S \downarrow+d \downarrow_{\mathrm{r}}+d \downarrow_{\mathrm{a}}\right) \cdot \alpha_{\mathrm{g}} \cdot \alpha_{\mathrm{a}}}{1.0-\alpha_{\mathrm{g}} \cdot \alpha_{\mathrm{a}}}$,

where $\alpha_{\mathrm{g}}$ is the albedo of the ground and $\alpha_{\mathrm{a}}$ is the albedo of the cloudless sky, computed as

$\alpha_{\mathrm{a}}=0.0685+\left(1.0-F_{\mathrm{c}}\right) \cdot\left(1-\tau_{\mathrm{as}}\right)$.

Finally $V_{\mathrm{s}}$ is the sky view factor, i.e., the fraction of sky visible in a point, computed using the algorithm presented in Corripio (2002).

\subsection{The shortwave radiation correction for cloudy sky, DEC-MOD's}

The radiation components presented in the previous subsections are computed under the assumption of cloudless sky conditions. To account for the presence of clouds, three decomposition models were implemented: Erbs et al. (1982), Reindl et al. (1990) , and Boland et al. (2001). The procedure described here is in line with Helbig et al. (2010). It corrects the clear sky direct and diffuse irradiance by means of adjustment coefficients and the clear sky irradiances so that, for any point

$S \downarrow^{*}=c_{\mathrm{S}} \cdot S \downarrow$

is the corrected irradiance for direct shortwave radiation (and $c_{\mathrm{S}}$ is the correction coefficient for $S \downarrow$ ), and

$d \downarrow^{*}=c_{\mathrm{d}} \cdot d \downarrow$

is the corrected irradiance for the diffuse shortwave radiation (and $c_{\mathrm{d}}$ is the correction coefficient for $d \downarrow$ ). The coefficients of reduction depend on the global shortwave irradiance measured at the available stations as suggested by Orgill and Hollands (1977), Erbs et al. (1982) and Reindl et al. (1990). For any station, $i$,

$$
\begin{aligned}
& R_{\mathrm{Sw}} \downarrow_{i}=S \downarrow_{i}^{*}+d^{*} \downarrow_{i}, \\
& d^{*} \downarrow_{i}=\left(k_{\mathrm{d}}\right)_{i} \hat{R}_{\mathrm{Sw}} \downarrow_{i} .
\end{aligned}
$$

Eq. (23) defines the diffuse sky fraction coefficient $k_{\mathrm{d}}$, (Liu and Jordan, 1960; Helbig et al., 2010) as the ratio between the diffuse sky radiation and the measured global radiation under generic sky conditions. Therefore, at stations,

$\left(c_{\mathrm{d}}\right)_{i}=\frac{R_{\mathrm{sw}} \downarrow_{i} \cdot\left(k_{\mathrm{d}}\right)_{i}}{d \downarrow_{i}}$

and

$\left(c_{\mathrm{s}}\right)_{i}=\frac{R_{\mathrm{SW}} \downarrow_{i} \cdot\left(1-\left(k_{\mathrm{d}}\right)_{i}\right)}{S \downarrow_{i}}$.

Clearly, $k_{\mathrm{d}}$ becomes the key parameter to be determined to approximate, for the stations, the estimation of the cloudy irradiances. To reach this goal, we use here three different parameterizations.

- Erbs et al. (1982) estimated $k_{\mathrm{d}}$ for latitudes between 31 and $42^{\circ} \mathrm{N}$, using hourly data from five irradiance measurement stations in the USA:

$$
k_{\mathrm{d}}= \begin{cases}1.0-0.09 k_{t} & \text { if } k_{t} \leq 0.22 \\ 0.951-0.1604 k_{t}+4.388 k_{t}^{2}-16.638 k_{t}^{3}+12.336 k_{t}^{4} & \text { if } 0.22<k_{t} \leq 0.80 \\ 0.165 & \text { if } k_{t}>0.80\end{cases}
$$

- Reindl et al. (1990) estimated the diffuse fraction $k_{\mathrm{d}}$ with known $k_{t}$ using data measured in the USA and Europe (latitude between $28-60^{\circ} \mathrm{N}$ ) and provided the relation:

$$
k_{\mathrm{d}}= \begin{cases}1.02-0.248 \cdot k_{t} & \text { if } k_{t} \leq 0.30 \\ 1.45-1.67 k_{t} & \text { if } 0.30<k_{t} \leq 0.78 \\ 0.147 & \text { if } k_{t}>0.78\end{cases}
$$

- Boland et al. (2001) by using data from Victoria, Australia, provided the exponential relation:

$$
k_{\mathrm{d}}=\frac{1.0}{1.0+e^{7.997\left(k_{t}-0.586\right)}} .
$$

Equation (22) above is completely determined by the knowledge of the clearness sky index, $k_{t}[-]$, which is defined as

$k_{t}=\frac{R_{\mathrm{sw}} \downarrow}{I_{\mathrm{sc}} \cdot E_{0} \cdot \cos \left(\theta_{\mathrm{s}}\right)}$.

Using the above equations a set of adjustment coefficients, $c_{\mathrm{S}}$ and $c_{\mathrm{d}}$ for beam and diffuse radiation components are obtained for any measurements station and at any time in which there is direct solar radiation. To extend it to any spatial point, the coefficients need to be extrapolated to all the points of interest (where incoming shortwave solar radiation is not measured). This is accomplished in NewAGE-DEC-MOD's by using the JGrass-NewAge kriging component (Formetta et al., 2011) and using a simple kriging algorithm (Goovaerts, 1997). 


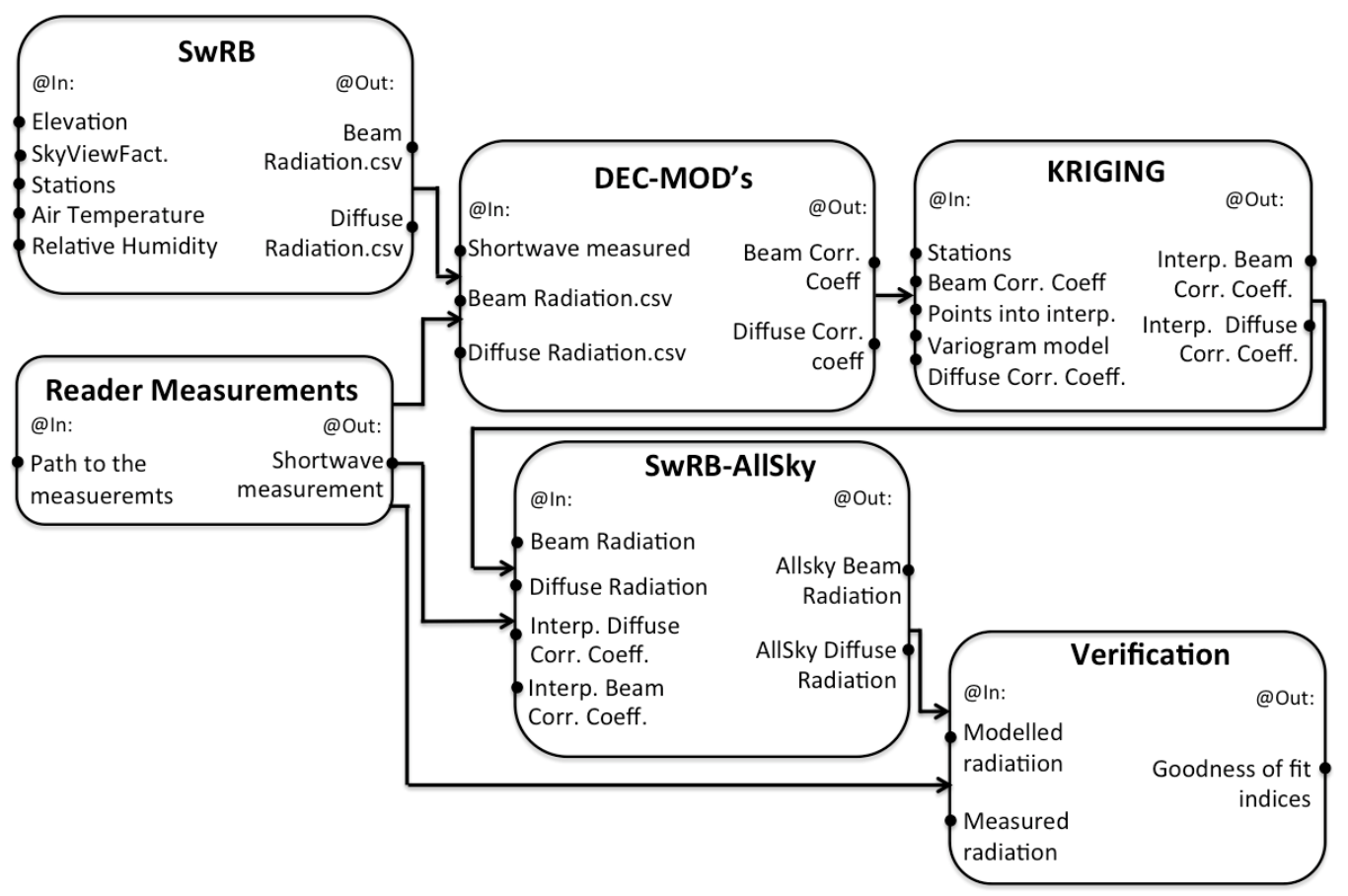

Fig. 1. OMS3 SWRB components of JGrass-NewAge and flowchart to model shortwave radiation at the terrain surface with generic sky conditions. Where not specified, quantity in input or output must be intended as a spatial field for any instant of simulation time. "Measured" refers to a quantity that is measured at a meteorological station. The components, besides the specified files received in input, include an appropriate set of parameter values.

\section{Applications}

The capability of the model was tested by combining four NewAge JGrass components within a OMS script: the SwRB, the (radiation decomposition model) DEC-MOD's, the kriging and the NewAGE-V (verification) package. Each package is represented in Fig. 1 by a rounded rectangle and the lines joining the rectangle represent the data that two packages exchange. According to the convention used, the component on the left provides data to the component on the right. The model is applied in two different modes: vector mode, providing the radiation results in a number of points defined by the user, and raster mode, providing the radiation result for each pixel of the analyzed basin. Below we described the basins used for the verification, comment their data, illustrate the verification procedure and finally, we present the raster mode application.

\subsection{Reference catchments}

Three different basins were used in this study: Little Washita River basin (Oklahoma, USA), Fort Cobb watershed (Oklahoma, USA) and Piave River basin (Veneto, Italy). As presented in the next subsections, differences between the two places in elevation range, number of monitoring points, latitudes, and complexity of the topography are substantial.
The Little Washita River basin $\left(611 \mathrm{~km}^{2}\right)$ is located in southwestern Oklahoma, between Chickasha and Lawton and its main hydrological and geological features are presented in Allen and Naney (1991). The elevation range is between $300 \mathrm{~m}$ and $500 \mathrm{~m}$ a.s.l., the main land uses are range, pasture, forest, and cropland. The mean annual precipitation is $760 \mathrm{~mm}$ and the mean air temperature is $16^{\circ} \mathrm{C}$. Seventeen meteorological stations of the ARS Micronet (http://ars.mesonet.org/) were used for the simulations and for each station there are five-minute measurements available of air temperature at a height of $1.5 \mathrm{~m}$, relative humidity at a height of $1.5 \mathrm{~m}$ and incoming global solar radiation. The data for the year 2002 were aggregated to an hourly time step to be used in the simulations. The meteorological station's main features are reported in Table 2. Figure 4 shows the Little Washita DEM and the location of the meteorological stations.

The Fort Cobb Reservoir basin $\left(813 \mathrm{~km}^{2}\right)$ is located in southwestern Oklahoma. An exhaustive description is given in Rogers (2007). The elevation range is between 400 and $570 \mathrm{~m}$ above the sea level, main land usages are cropland, range, pasture, forest, and water. The long record mean annual precipitation is $816 \mathrm{~mm}$ and the mean annual air temperature is $18^{\circ} \mathrm{C}$. Eight meteorological stations of the ARS Micronet are used for the simulations. The data for the year 


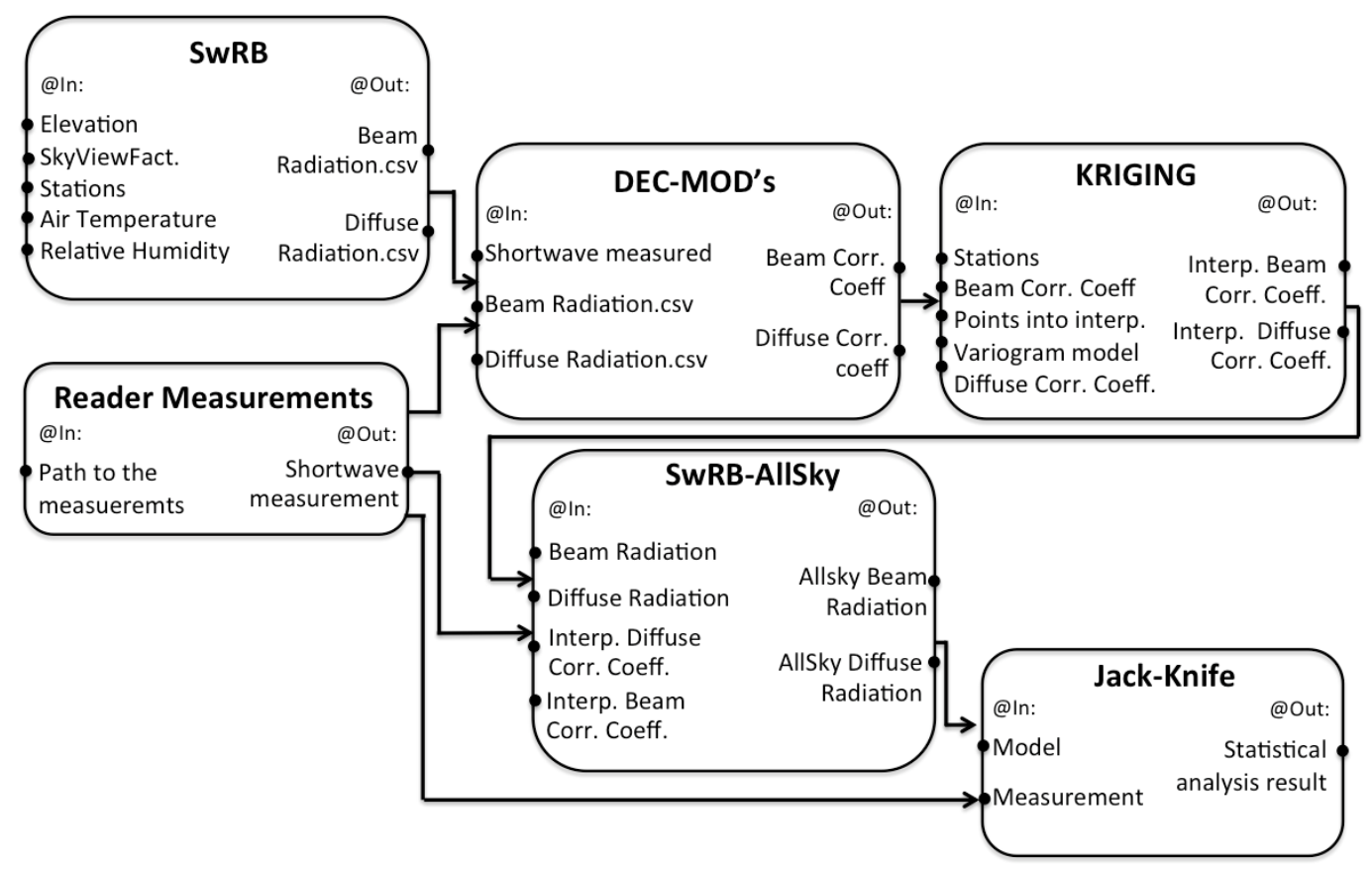

Fig. 2. OMS3 SWRB components of JGrass-NewAge and flowchart for automatic jackknife procedure. The jackknife component (which is not used in the present paper) simply needs to be added to the basic model solution, and actually just substitutes the the verification component in Fig. 1

Table 2. List of the meteorological stations used in the simulations performed on the Little Washita River basin. ID is the station identification number, city refers to the closest city to the station, Lat. and Long. stand for latitude and longitude, respectively, and elevation and aspect refer to the respective station. Bold font is used to indicate the stations belonging to the validation set.

\begin{tabular}{llccrr}
\hline ID & City & $\begin{array}{c}\text { Lat. } \\
\left({ }^{\circ}\right.\end{array}$ & $\begin{array}{c}\text { Long. } \\
\left({ }^{\circ}\right)\end{array}$ & $\begin{array}{r}\text { Elevation } \\
(\mathrm{m})\end{array}$ & $\begin{array}{r}\text { Aspect } \\
\left({ }^{\circ}\right)\end{array}$ \\
\hline $\mathbf{1 2 4}$ & Norge & $\mathbf{3 4 . 9 7 2 8}$ & $\mathbf{- 9 8 . 0 5 8 1}$ & $\mathbf{3 8 7}$ & $\mathbf{1 3 8}^{\circ}$ \\
131 & Cyril & 34.9503 & -98.2336 & 458 & $245^{\circ}$ \\
133 & Cement & 34.9492 & -98.1281 & 430 & $116^{\circ}$ \\
134 & Cement & 34.9367 & -98.0753 & 384 & $65^{\circ}$ \\
135 & Cement & 34.9272 & -98.0197 & 366 & $182^{\circ}$ \\
136 & Ninnekah & 34.9278 & -97.9656 & 343 & $270^{\circ}$ \\
144 & Agawam & 34.8789 & -97.9172 & 388 & $50^{\circ}$ \\
146 & Agawam & 34.8853 & -98.0231 & 358 & $212^{\circ}$ \\
$\mathbf{1 4 8}$ & Cement & $\mathbf{3 4 . 8 9 9 2}$ & $-\mathbf{9 8 . 1 2 8 1}$ & $\mathbf{4 3 1}$ & $\mathbf{1 6 0}^{\circ}$ \\
149 & Cyril & 34.8983 & -98.1808 & 420 & $205^{\circ}$ \\
$\mathbf{1 5 0}$ & Cyril & $\mathbf{3 4 . 9 0 6 1}$ & $-\mathbf{9 8 . 2 5 1 1}$ & $\mathbf{4 3 1}$ & $\mathbf{1 9 5}^{\circ}$ \\
153 & Cyril & 34.8553 & -98.2121 & 414 & $165^{\circ}$ \\
154 & Cyril & 34.8553 & -98.1369 & 393 & $175^{\circ}$ \\
156 & Agawam & 34.8431 & -97.9583 & 397 & $290^{\circ}$ \\
159 & Rush Springs & 34.7967 & -97.9933 & 439 & $235^{\circ}$ \\
162 & Sterling & 34.8075 & -98.1414 & 405 & $15^{\circ}$ \\
$\mathbf{1 8 2}$ & Cement & $\mathbf{3 4 . 8 4 5}$ & $-\mathbf{9 8 . 0 7 3 1}$ & $\mathbf{3 7 0}$ & $\mathbf{2 4 5}^{\circ}$ \\
\hline
\end{tabular}

Geosci. Model Dev., 6, 915-928, 2013
Table 3. List of the meteorological stations used in the simulations performed on the Fort Cobb Reservoir basin. Clarification of column headings as in Table 2 .

\begin{tabular}{clccrr}
\hline ID & City & $\begin{array}{c}\text { Lat. } \\
\left({ }^{\circ}\right)\end{array}$ & $\begin{array}{c}\text { Long. } \\
\left({ }^{\circ}\right)\end{array}$ & $\begin{array}{r}\text { Elevation } \\
(\mathrm{m})\end{array}$ & $\begin{array}{r}\text { Aspect } \\
\left({ }^{\circ}\right)\end{array}$ \\
\hline $\mathbf{1 0 1}$ & Hydro & $\mathbf{3 5 . 4 5 5 1}$ & $\mathbf{- 9 8 . 6 0 6 4}$ & $\mathbf{5 0 4}$ & $\mathbf{1 2 0}^{\circ}$ \\
104 & Colony & 35.3923 & -98.6233 & 484 & $35^{\circ}$ \\
$\mathbf{1 0 5}$ & Colony & $\mathbf{3 5 . 4 0 7 2}$ & $\mathbf{- 9 8 . 5 7 1}$ & $\mathbf{4 9 3}$ & $\mathbf{3 0 0}^{\circ}$ \\
106 & Eakly & 35.3915 & -98.5138 & 472 & $295^{\circ}$ \\
108 & Eakly & 35.3611 & -98.5712 & 492 & $40^{\circ}$ \\
$\mathbf{1 0 9}$ & Eakly & $\mathbf{3 5 . 3 1 2 3}$ & $\mathbf{- 9 8 . 5 6 7 5}$ & $\mathbf{4 6 6}$ & $\mathbf{9 0}^{\circ}$ \\
110 & Eakly & 35.3303 & -98.5202 & 430 & $115^{\circ}$ \\
113 & Colony & 35.291 & -98.6357 & 465 & $155^{\circ}$ \\
\hline
\end{tabular}

2006 were aggregated to an hourly time step and used in the simulations.

The meteorological stations' main features are reported in Table 3 and Fig. 5 shows their position.

The Piave River basin area $\left(3460 \mathrm{~km}^{2}\right)$ is located in the northeastern part of the Italian peninsula. The elevation range is between 700 and $3160 \mathrm{~m}$ a.s.l., the main soil uses are (i) crops up to $500 \mathrm{~m}$ a.s.l., (ii) evergreen and deciduous forests at elevations between 500 and $1800 \mathrm{~m}$ a.s.l., and (iii) alpine pasture and rocks at higher elevations. The mean annual precipitation is around $1500 \mathrm{~mm}$ and the mean air temperature is $10^{\circ} \mathrm{C}$. 
Table 4. List of the meteorological stations used in the simulations performed on the Piave River basin. Clarification of column headings as in Table 2.

\begin{tabular}{clccrr}
\hline ID & City & $\begin{array}{c}\text { Lat. } \\
\left({ }^{\circ}\right)\end{array}$ & $\begin{array}{c}\text { Long. } \\
\left({ }^{\circ}\right)\end{array}$ & $\begin{array}{r}\text { Elevation } \\
(\mathrm{m})\end{array}$ & $\begin{array}{r}\text { Aspect } \\
\left({ }^{\circ}\right)\end{array}$ \\
\hline 1 & Arabba & 46.4999 & 11.8761 & 1825 & $180^{\circ}$ \\
$\mathbf{2}$ & Caprile & $\mathbf{4 6 . 4 4 0 4}$ & $\mathbf{1 1 . 9 9 0 0}$ & $\mathbf{1 0 2 5}$ & $\mathbf{1 7 0}^{\circ}$ \\
3 & Agordo & 46.2780 & 12.0331 & 602 & $5^{\circ}$ \\
8 & Villanova & 46.4433 & 12.2062 & 972 & $71^{\circ}$ \\
$\mathbf{9}$ & Auronzo & $\mathbf{4 6 . 5 5 6 2}$ & $\mathbf{1 2 . 4 2 5 8}$ & $\mathbf{9 4 0}$ & $\mathbf{2 2 3}^{\circ}$ \\
11 & Campo di Zoldo & 46.3466 & 12.1841 & 915 & $160^{\circ}$ \\
12 & Domegge di Cadore & 46.4609 & 12.4103 & 802 & $148^{\circ}$ \\
14 & Monte Avena & 46.0321 & 11.8271 & 761 & $55^{\circ}$ \\
18 & Passo Pordoi & 46.4834 & 11.8224 & 357 & $55^{\circ}$ \\
21 & Passo Monte Croce & 46.6521 & 12.4239 & 1612 & $120^{\circ}$ \\
22 & Col Indes & 46.1191 & 12.4401 & 1119 & $210^{\circ}$ \\
$\mathbf{2 3}$ & Torch & $\mathbf{4 6 . 1 5 1 5}$ & $\mathbf{1 2 . 3 6 2 9}$ & $\mathbf{6 0 2}$ & $\mathbf{1 7 7}^{\circ}$ \\
26 & Sappada & 46.5706 & 12.7080 & 1275 & $156^{\circ}$ \\
29 & Feltre & 46.0162 & 11.8946 & 273 & $190^{\circ}$ \\
31 & Falcade & 46.3554 & 11.8694 & 1151 & $50^{\circ}$ \\
32 & Cortina & 46.536 & 12.1273 & 1244 & $88^{\circ}$ \\
35 & Belluno & 46.1643 & 12.2450 & 378 & $157^{\circ}$ \\
\hline & & & & & \\
\hline
\end{tabular}

Seventeen meteorological stations are used for the simulations and for each station there are five-minute measurements available for air temperature at a height of $1.5 \mathrm{~m}$, relative humidity at a height of $1.5 \mathrm{~m}$ and incoming global solar radiation. The data for the year 2010 were aggregated to an hourly time step and were used in the simulations. The meteorological stations' main features are reported in Table 4 and Fig. 6 shows their position.

\subsection{Plan of simulations and verification method}

The SwRB component estimates for any point of a basin the incoming radiation. In principle, it does not require any calibration, once the four parameters in Table 1 are assigned according to literature values. Because the model is an OMS3 component, its parameters could be also calibrated by using one of the OMS3 NewAge-JGrass calibration algorithms (Luca, Hay et al., 2006; and particle swarm, Kennedy and Eberhart, 1995). The model outputs, however, do not correspond to a measured quantity but to an intermediate step of the calculations. Only the data produced from the DECMOD's component corresponds to measured quantities, and this component uses the measured quantity to estimate the attenuation coefficients. Therefore, to allow for some validation, we divided any of the group of measurement stations into two subgroups: one used for the estimation of the coefficients, (C-set), and the other for the verification of the results, (V-set). Stations used for verification are in bold letters in Tables 2, 3 and 4. More complex verification strategies could be used, as described in the discussion section, but their application is beyond the scope of the present work.
Therefore, for any of the three basins we applied

- the SwRB in the subset of the measurement stations. The result of this step is the computation of the clear sky surface shortwave radiation. Inputs and outputs of the model are reported in Table 1. The main parameter values used in the simulations are reported in Table 1 according to Iqbal (1983) and Corripio (2002);

- the DEC-MOD's presented in the previous section and estimation of the coefficients $c_{\mathrm{s}}$ and $c_{\mathrm{d}}$. Inputs and outputs of the model are reported in Fig. 1;

- the ordinary kriging component (Formetta et al., 2011) to extrapolate the coefficients $c_{\mathrm{s}}$ and $c_{\mathrm{d}}$ for the set of stations left for verification (in bold in Tables 2, 3 and 4);

- an estimate of the shortwave incoming solar radiation under generic sky conditions in the V-set (SwRBAllsky, which multiply the SwRB output by the correction coefficient's kriging output for the V-Set stations);

- the verification component NewAGE-V (Formetta et al., 2011) to evaluate the performance of the model.

For the simulations of this paper, the Reindl model was used in the case of Piave River basin and Erbs model was used for Little Washita and Fort Cobb catchments. This choice was made because the Erbs model was estimated by using USA measurements and the Reindl model was estimated by using European measurements.

For verification we used three indexes of performance:

- mean absolute error (MAE):

$\mathrm{MAE}=\frac{1}{N} \cdot \sum_{i}^{N}\left|S_{i}-O_{i}\right|$,

where $N$ is the number of records of the time series, $O$ are the observed values and $S$ are the simulated values. MAE is expressed in the same units of $O$ and $S$, and is zero for perfect agreement between observations and estimates.

- percentual bias (PBIAS):

PBIAS $=100 \cdot \frac{\sum_{i}^{N}\left(S_{i}-O_{i}\right)}{\sum_{i}^{N} O_{i}}$,

PBIAS measures the average tendency of the simulated values to be larger or smaller than their observed ones. The optimal value of PBIAS is zero, with lowmagnitude values indicating accurate model simulation.

- Kling-Gupta efficiency (KGE) as reported in Gupta et al. (2009):

$\mathrm{KGE}=1-\sqrt{(R-1)^{2}+(A-1)^{2}+(B-1)^{2}}$, 


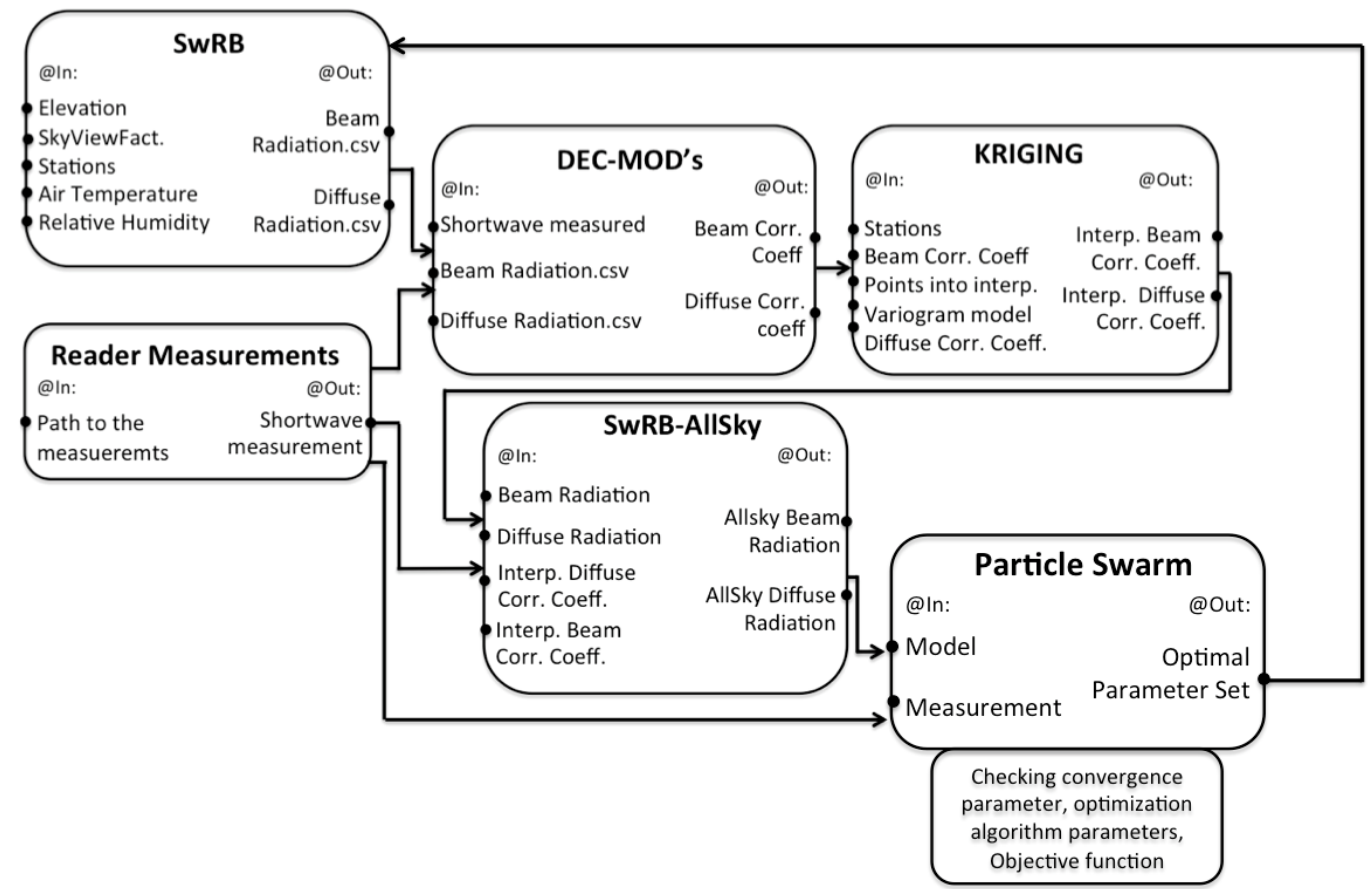

Fig. 3. OMS3 SWRB components of JGrass-NewAge and flowchart for model parameter calibration. In this case, to the basic model solution the particle swarm controller is added, which iterates model runs over the appropriate number of parameters set until the appropriate optimization is obtained.
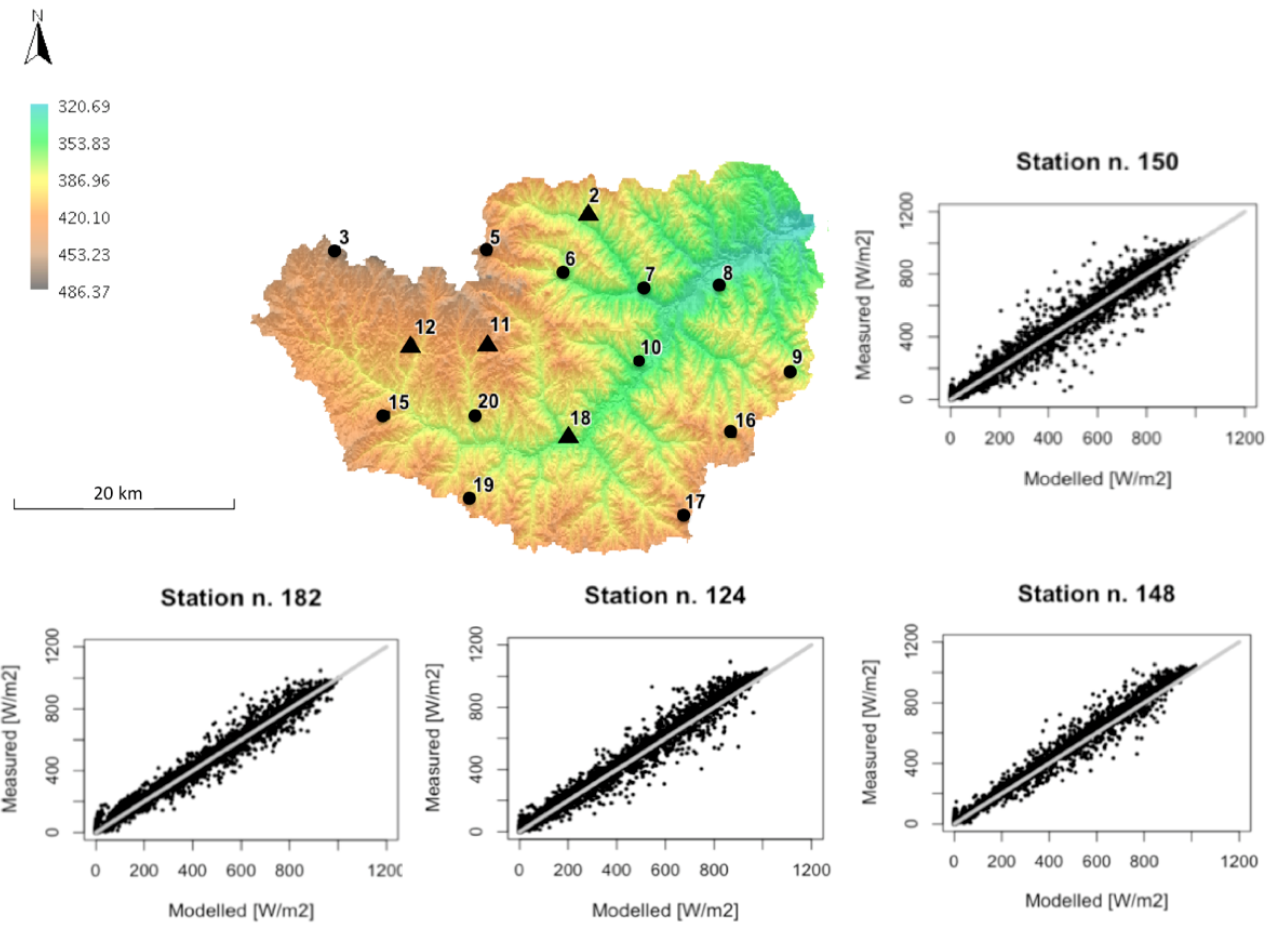

Fig. 4. The Little Washita River basin, Oklahoma (USA). Triangles represent the verification set (V-set) and circles represent the calibration set (C-set). The comparison between measured and modeled incoming solar radiation is represented with scatter plots. 

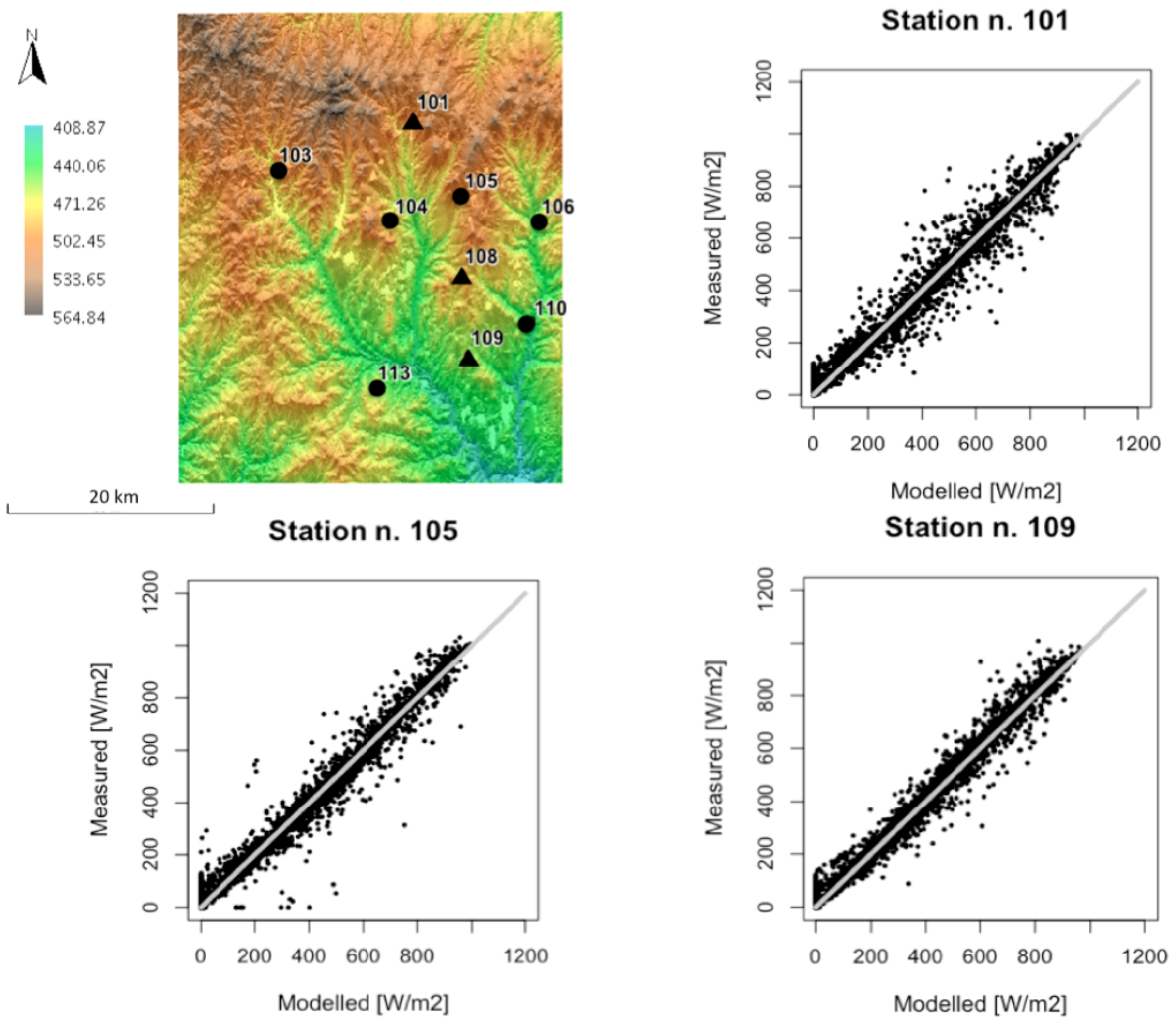

Fig. 5. The Fort Cobb Reservoir basin, Oklahoma (USA). Triangles represent the V-set and circles represent the C-set. The comparison between measured and modeled incoming solar radiation is represented with scatter plots.

in which $R$ represents the linear correlation coefficient between the $S$ and $O$ values, $A$ and $B$ are, respectively expressed in Eqs. (33) and (34):

$A=\frac{\sigma_{\mathrm{o}}}{\sigma_{\mathrm{s}}}$

where $\sigma_{\mathrm{o}}$ is the observed standard deviation value and $\sigma_{\mathrm{s}}$ is the simulated standard deviation value;

$B=\frac{\mu_{\mathrm{s}}-\mu_{\mathrm{o}}}{\sigma_{\mathrm{o}}}$,

where $\mu_{\mathrm{s}}$ and $\mu_{\mathrm{o}}$ are the means of $S$ and $O$ values. For this index, the best agreement is represented with the value 1 .

The kriging package can utilize the most common variogram models (spherical, linear, exponential, gaussian). However, for the cases below only a linear model was used.

\subsection{Raster mode application on the Piave River basin}

In order to show the capability of the system in providing solar radiation maps, a raster mode simulation was set up for the Piave River basin. Different from the previous vector mode applications, the model results are computed for each point of the Piave River basin. In order to perform this application it was necessary to interpolate the air temperature and relative humidity measurement data for each pixel of the basins by using a detrended kriging component. The simulation time step was hourly and the simulation period was one day: from 1 January 2010 to 1 February 2010.

\section{Results}

Results are presented separately for the three case studies. They confirm the results found in the literature, and reveal a reasonable agreement between measured and simulated data.

\subsection{Results for the Little Washita River basin}

Figure 4 (top right, bottom left and bottom right) shows the scatter plot between the modeled and the measured total incoming solar radiation in the four stations of the V-set.

Table 5 shows the result of the NewAge- $V$, which accepts as input measured and modeled time series and provides as output the user defined goodness of fit indexes. 

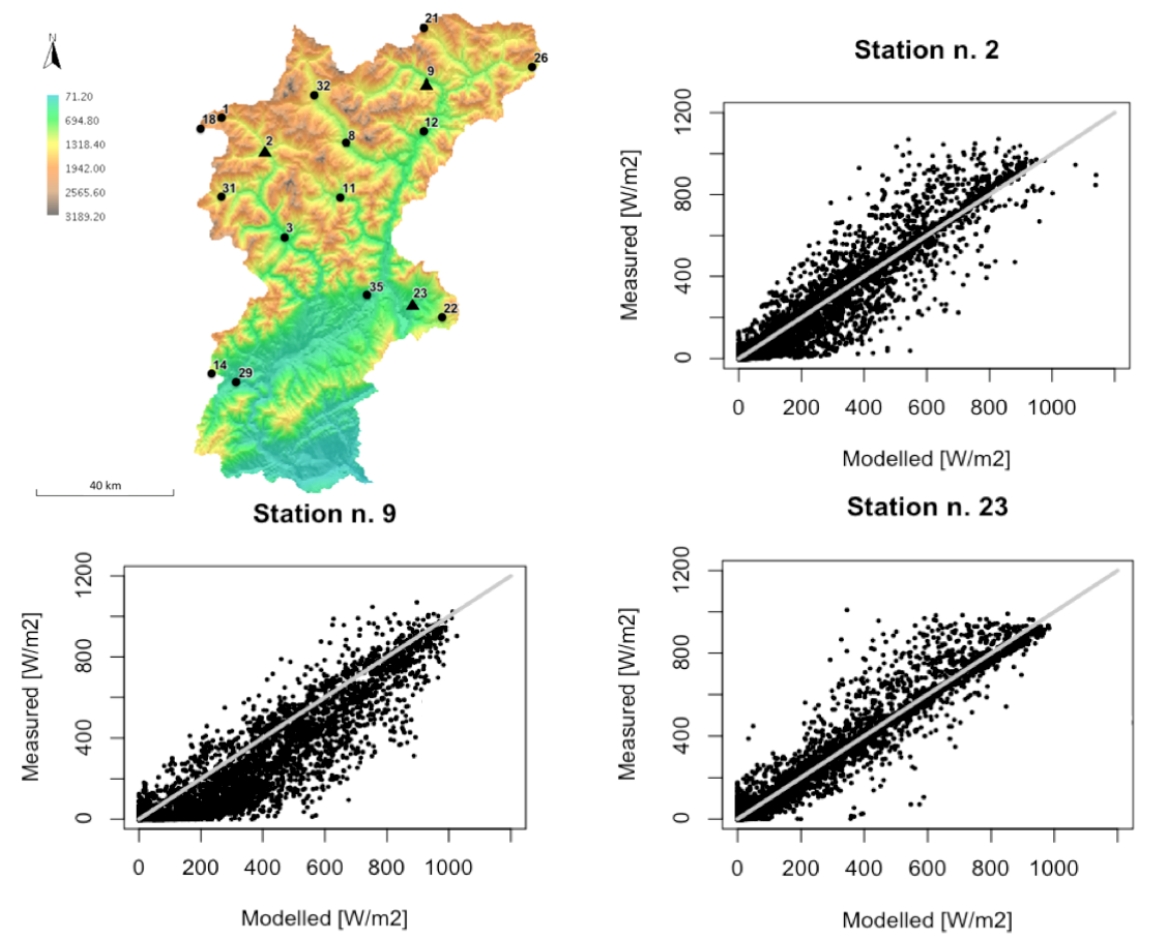

Fig. 6. River Piave area (Italy). Triangles represent V-set and circles represent C-set. The comparison between measured and modeled incoming solar radiation is represented with scatter plots.

Table 5. Index of goodness of fit between modeled and measured solar radiation on the Little Washita River basin.

\begin{tabular}{cccc}
\hline STATION ID & KGE & MAE $\left[\mathrm{W} \mathrm{m}^{-2}\right.$ ] & PBIAS [\%] \\
\hline 148 & 0.94 & 16.65 & 4.90 \\
124 & 0.95 & 17.50 & 3.80 \\
182 & 0.98 & 16.50 & 1.80 \\
150 & 0.97 & 17.90 & 2.10 \\
\hline
\end{tabular}

\subsection{Results for Fort Cobb Reservoir basin}

For the Fort Cobb Reservoir, the same procedure presented for the Little Washita River basin was followed.

Figure 5 (top right, bottom left and bottom right) shows the scatter plot between the modeled and the measured total incoming solar radiation in the four V-set stations. Table 6 shows the results in term of goodness of fit indices for the V-set.

\subsection{Results for Piave River basin}

For the Piave River basin the same procedure as presented for the Little Washita River basin was applied. The decomposition model used in this case was Reindl et al. (1990). Figure 6 (top right, bottom left and bottom right) shows the scatter plot between the modeled and the measured total incoming solar
Table 6. Index of goodness of fit between modeled and measured solar radiation on the Fort Cobb Reservoir basin.

\begin{tabular}{cccc}
\hline STATION ID & KGE & MAE $\left[\mathrm{W} \mathrm{m}^{-2}\right]$ & PBIAS [\%] \\
\hline 101 & 0.96 & 15.6 & 5.5 \\
105 & 0.95 & 13.50 & 2.80 \\
109 & 0.97 & 14.07 & 2.70 \\
\hline
\end{tabular}

Table 7. Index of goodness of fit between modeled and measured solar radiation on the Piave River basin.

\begin{tabular}{cccc}
\hline STATION ID & KGE & MAE $\left[\mathrm{W} \mathrm{m}^{-2}\right]$ & PBIAS [\%] \\
\hline 2 & 0.92 & 4.53 & 2.7 \\
9 & 0.89 & 22.10 & 14.80 \\
23 & 0.95 & 3.58 & 2.1 \\
\hline
\end{tabular}

radiation in the four V-set. Table 7 shows the results in term of goodness of fit indexes for the same set of stations.

Finally, Fig. 7 presents the maps resulting from the raster mode application. The four different radiation maps show the solar radiation (direct and diffuse) for four different hours (09:00, 12:00, 14:00 and 16:00 local time, LT) of the day 1 October 2010. Points in shadows obviously receive diffuse radiation and therefore shadows are never completely dark. 


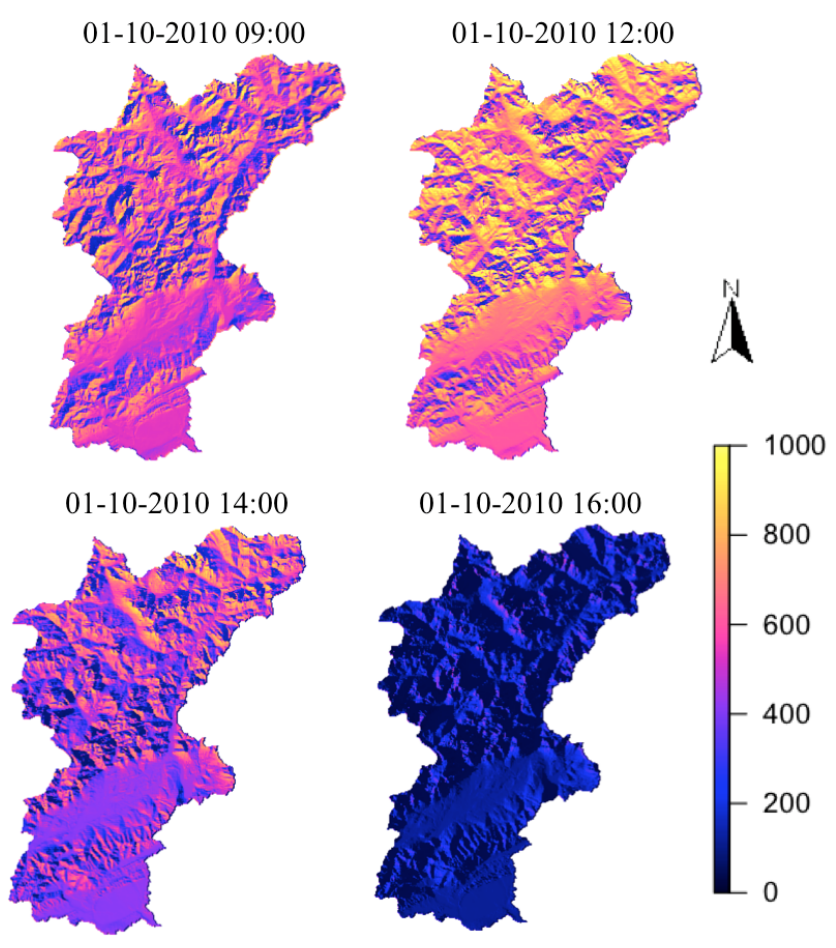

Fig. 7. The figure represents the global shortwave radiation on the Piave area on 1 October 2010 at four different hours of the day. During the day, differently oriented hillslope received the maximum amount of radiation and, at 16:00 LT most of the area is covered by shadows.

\section{Discussion}

\subsection{About the SwRB and DRM components' predictive capabilities}

The model applications are performed in case studies where topography has different characteristics: (a) two cases presented gentle topography and high density measurement network (for the experimental Little Washita and Fort Cobb watersheds), and (b) the other case presented a typical hydrological basin with complex topography, high elevation range and few monitoring stations.

In all the cases the model was able to simulate the global shortwave radiation showing relatively good goodness of fit indices as presented in Tables 5 and 6 for Little Washita and Fort Cobb, respectively, and in Table 7 for the Piave River basin.

The model performs with the similar and acceptable accuracy both for Little Washita and Fort Cobb basins. The result is confirmed by the goodness of fit indices and by the graphical analysis.

The model performance deteriorated in the Piave case study. This could be due to the effect of the complex topography on the computation of the clear sky solar radiation but also due to the lower measurement station density in high elevation zones.

Because of this topographic condition the increasing measurement data uncertainty of the temperature and humidity influenced the atmospheric transmittance computations. This is confirmed also by the data analysis: for the Piave River basin measurements show lower correlation compared to, for example, the correlation between measurements at the Little Washita River basin, where the gentle topography does not play a crucial role.

Regardless, the model was able to reproduce well the shortwave solar radiation also in the case of complex topography. The PBIAS index was equal to 14.80 in the worst case. According the hydrological model classification based on PBIAS index, presented in Van Liew et al. (2005) and Stehr et al. (2008), the results achieved in our study are classified as "good" and therefore the solar radiation model is suitable to be used for the estimation of incoming shortwave solar radiation.

Finally, Fig. 7 presents the raster mode application of the model. Maps of incoming solar radiation are presented for four hours during the daytime. The effect of the complex topographic feature of the Piave River basin is evident in the radiation maps. Their patterns change during the daytime according to the solar position, the surrounding terrain, and the shadow.

\subsection{About the possibilities open by the components- based JGrass-NewAGE system}

Since the goal of the paper was to show how the components work, the statistical analysis of the results was maintained to a simple level. One more accurate procedure of testing the components' performances would be to apply a jackknife procedure to estimate errors (as proposed by Quenouille, 1956; Miller, 1974). In this procedure, the V-set, would vary among all the stations and an overall statistic could be delineated.

According to Tovar et al. (1995) and Long and Ackerman (1995) studies, the influence of the aspect of the measurement station could have been identified. This operation and analysis is time consuming. It can be possible simply by adding a jackknife component to the structure of the model at "link time", i.e., using the script that connects the components. Figure 2 shows the modeling solution that is necessary to apply a jackknife strategy. No modification of the single components is necessary to accomplish the task, only their re-arrangements with the addition of the new jackknife component that performs the permutation of the calibration sites.

Other components in the New-AGE system (Formetta et al., 2011) allow to perform parameter calibration. In this study, no calibration of the four parameters (in Table 1) that are needed to run the SwRB component was performed. However, it can be easily envisioned using the particle swarm 
Table 8. List of symbols.

\begin{tabular}{|c|c|c|}
\hline Symbol & Name & Unit \\
\hline$c_{\mathrm{d}}$ & Adjustment coefficient for $d \downarrow$ & {$[-]$} \\
\hline$c_{\mathrm{S}}$ & Adjustment coefficient for $S \downarrow$ & {$[-]$} \\
\hline$d \downarrow$ & Total diffuse irradiance & {$\left[\mathrm{W} \mathrm{m}^{-2}\right]$} \\
\hline$d \downarrow_{\mathrm{r}}$ & Diffuse irradiance component due to Rayleigh's scattering & {$\left[\mathrm{W} \mathrm{m}^{-2}\right]$} \\
\hline$d \downarrow_{\mathrm{a}}$ & Diffuse irradiance component due to aerosol scattering & {$\left[\mathrm{W} \mathrm{m}^{-2}\right]$} \\
\hline$d \downarrow_{\mathrm{m}}$ & Diffuse irradiance component due to multiple reflections & {$\left[\mathrm{W} \mathrm{m}^{-2}\right]$} \\
\hline$k_{\mathrm{d}}$ & Diffuse sky fraction & {$[-]$} \\
\hline$k_{t}$ & Clearness sky index & {$[-]$} \\
\hline$l_{\mathrm{o}}$ & Vertical ozone layer thickness & {$[\mathrm{cm}]$} \\
\hline$m_{\mathrm{a}}$ & Relative air mass & {$[-]$} \\
\hline$m_{\mathrm{r}}$ & Relative optical air mass & {$[-]$} \\
\hline$w$ & Precipitation water & {$[\mathrm{cm}]$} \\
\hline$p$ & Air pressure & [mb] \\
\hline$C_{1}$ & Constant in equation (1) & {$[-]$} \\
\hline$E_{0}$ & Correction for Earth's orbit eccentricity & {$[-]$} \\
\hline$F_{\mathrm{c}}$ & Forward scattering to total scattering & {$[-]$} \\
\hline$I_{\mathrm{Sc}}$ & Solar constant & {$\left[\mathrm{W} \mathrm{m}^{-2}\right]$} \\
\hline$\hat{I}_{\mathrm{Sc}}$ & Modified solar constant & {$\left[\mathrm{W} \mathrm{m}^{-2}\right]$} \\
\hline$N$ & Day number & {$[-]$} \\
\hline$R_{\mathrm{SW}} \downarrow$ & All-sky irradiance for shortwave radiation on a sloping surface & {$\left[\mathrm{W} \mathrm{m}^{-2}\right]$} \\
\hline$S \downarrow$ & Cloudless incident direct shortwave radiation on a sloping surface & {$\left[\mathrm{W} \mathrm{m}^{-2}\right]$} \\
\hline$S \downarrow^{*}$ & All-sky incident direct shortwave radiation on a sloping surface & {$\left[\mathrm{W} \mathrm{m}^{-2}\right]$} \\
\hline$T_{\mathrm{S}}$ & Products of atmospheric transmittances & {$[-]$} \\
\hline$V$ & Visibility & {$[\mathrm{km}]$} \\
\hline$V_{\mathrm{s}}$ & Sky-view factor & {$[-]$} \\
\hline$\alpha_{\mathrm{a}}$ & Albedo of the cloudless sky & {$[-]$} \\
\hline$\alpha_{\mathrm{g}}$ & Ground albedo & {$[-]$} \\
\hline$\beta_{\mathrm{S}}$ & Correction factor for increasing of transmittance with elevation & {$[-]$} \\
\hline$\kappa$ & Day angle & [rad] \\
\hline$\theta_{\mathrm{S}}$ & Angle between Sun vector and surface tangent plane & [rad] \\
\hline$\theta_{\mathrm{Z}}$ & Zenith angle & [rad] \\
\hline$\psi$ & Shadows index & {$[-]$} \\
\hline$\tau_{\mathrm{r}}$ & Rayleigh's scattering transmittance & {$[-]$} \\
\hline$\tau_{0}$ & Ozone transmittance & {$[-]$} \\
\hline$\tau_{\mathrm{g}}$ & Uniformly mixed gases transmittance & {$[-]$} \\
\hline$\tau_{\mathrm{W}}^{\circ}$ & Water vapor transmittance & {$[-]$} \\
\hline$\tau_{\mathrm{a}}$ & Aerosol transmittance & {$[-]$} \\
\hline$\tau_{\mathrm{aa}}$ & Transmittance of direct radiation due to aerosol absorbance & {$[-]$} \\
\hline$\tau_{\mathrm{as}}$ & Ratio between $\tau_{\mathrm{a}}$ and $\tau_{\mathrm{aa}}$ coefficients & {$[-]$} \\
\hline$\omega_{0}$ & Single scattering albedo fraction & \\
\hline
\end{tabular}

NewAge component (Formetta et al., 2011) for automatic calibration. In this case, the diagram of the linked components would be the one shown in Fig. 3, where to the configuration of Fig. 1 is added the configuration of the particle swarm controller component. Eventually, the four parameters can become variable in space and it would become reasonable to use the kriging spatial interpolators to generate their spatial structure. This would allow for studying the spatial variability of radiative transmittance with location or other characteristics as height, aspect, and slope of the terrain.

All of these simulations (Formetta et al., 2013) do not require any rewriting of the code, except the adjustment of the scripts to execute them. With the addition of more complexity, derived from adding a component or making spatial a parameter set, the improvement on the final results can be objectively determined with the goodness of fit component. The user can objectively judge if such introduction of complexities is worthwhile.

\section{Conclusions}

The goal of this paper was to present a new set of components for shortwave radiation modeling under generic sky 
conditions. These components use the object modeling system v3 to implement encapsulation and other object oriented features that make possible a flexible modeling structure apt to investigate many scientific questions with a minimum of effort.

The core components presented in this paper cover the simulation of the incoming shortwave radiation under cloudless conditions, and the estimation of the effects of clouds with three different parameterizations of the irradiance reduction. Main ancillary components used in the paper are the JGrass-V and the kriging components, respectively for the verification of the results, and the spatial interpolation of irradiance reduction characteristics.

The outputs provided by the model composition are independent of both the simulation time step and of the spatial resolution. This means that they can be integrated in both semi-distributed hydrological models and fully distributed hydrological models (once these models follow the requirements of OMS3). The paper presented both the vector and the raster mode applications and showed the flexibility of the model, which is able to be linked both to semi-distributed and to fully distributed hydrological models.

The theoretical formulation of the model composition used in the paper is tested by using three datasets from different watersheds (different geomorphological and climatological features) with good results as quantified by some objective indexes.

The model is comprised of OMS3 components and is able to use all of the JGrass-NewAge components such as the GIS visualization tools inherited from uDig (http://udig. refractions.net), and being connected to other components, for calibration of the parameters, estimation of long wave radiation, evapotranspiration and discharge, and for snow modeling, as presented in Formetta et al. (2011).

If another parameterization of the same radiation processes will be introduced in the future, it will simply constitute an alternative component that could be inserted by adding or eliminating it from the simulation script just before the run time, without altering any other piece of the modeling solution.

The model code used for the applications presented in this paper will be soon available on https://code.google.com/p/jgrasstools/. For any request contact giuseppe.formetta@unical.it

Acknowledgement. This paper has been partially produced with financial support from the HydroAlp project, financed by the Province of Bolzano. The authors thank Andrea Antonello and Silvia Franceschi (Hydrologists), and Daniele Andreis for their work on preliminary versions of parts of the codes.

Edited by: J. Neal

\section{References}

Allen, P. and Naney, J.: Hydrology of the Little Washita River Watershed, Oklahoma: Data and Analyses, USDA-ARS, ARS-90, December, 1991.

Bird, R. and Hulstrom, R.: Simplified clear sky model for direct and diffuse insolation on horizontal surfaces, Tech. rep., Solar Energy Research Inst., Golden, CO (USA), 1981.

Boland, J., Scott, L., and Luther, M.: Modelling the diffuse fraction of global solar radiation on a horizontal surface, Environmetrics, 12, 103-116, 2001.

Corripio, J.: Modelling the energy balance of high altitude glacierised basins in the Central Andes., Ph.D. dissertation, University of Edinburgh, 2002.

Corripio, J.: Vectorial algebra algorithms for calculating terrain parameters from DEMs and solar radiation modelling in mountainous terrain, Int. J. Geogr. Inf. Sci., 17, 1-24, 2003.

David, O., Markstrom, S., Rojas, K., Ahuja, L., and Schneider, I.: The object modeling system. Agricultural system models in field research and technology transfer, Press LLC, Chapter 15, 317333, 2002.

David, O., Ascough, J., Leavesley, G., and Ahuja, L.: Rethinking modeling framework design: object modeling system 3.0, in: IEMSS 2010 International Congress on Environmental Modeling and Software Modeling for Environments Sake, edited by: Swayne, D. A., Yang, Q., Voinov, A., Rizzoli, A., and Filatova, T., Fifth Biennial Meeting, 5-8 July 2010, Ottawa, Canada; 1183-1191, 2010.

Donatelli, M., Carlini, L., and Bellocchi, G.: A software component for estimating solar radiation, Environ. Model. Softw., 21, 411416, 2006.

Dozier, J. and Frew, J.: Rapid calculation of terrain parameters for radiation modeling from digital elevation data, IEEE T. Geosci. Remote, 28, 963-969, 1990.

Dubayah, R.: Modeling a solar radiation topoclimatology for the Rio Grande River Basin, J. Veg. Sci., 5, 627-640, 1994.

Dubayah, R. and Paul, M.: Topographic solar radiation models for GIS, Int. J. Geogr. Inf. Sys., 9, 405-419, 1995.

Duguay, C.: Radiation modeling in mountainous terrain review and status, Mountain Res. Develop., 13, 339-357, 1993.

Erbs, D., Klein, S., and Duffie, J.: Estimation of the diffuse radiation fraction for hourly, daily and monthly-average global radiation, Solar Energy, 28, 293-302, 1982.

Formetta, G., Mantilla, R., Franceschi, S., Antonello, A., and Rigon, R.: The JGrass-NewAge system for forecasting and managing the hydrological budgets at the basin scale: models of flow generation and propagation/routing, Geosci. Model Dev., 4, 943-955, doi:10.5194/gmd-4-943-2011, 2011.

Formetta, G., Chavez, J., David, O., and Rigon, R.: Shortwave radiation variability on complex terrain, Geosci. Model Dev. Discuss., in preparation, 2013.

$\mathrm{Fu}$, P. and Rich, P.: The solar analyst 1.0 user manual, Helios Environmental Modeling Institute, 1616 Vermont St KS, 66044 USA, 2000.

Goovaerts, P.: Geostatistics for Natural Resources Evaluation, Oxford University Press, USA, 1997.

Gubler, S., Gruber, S., and Purves, R. S.: Uncertainties of parameterized surface downward clear-sky shortwave and allsky longwave radiation., Atmos. Chem. Phys., 12, 5077-5098, doi:10.5194/acp-12-5077-2012, 2012. 
Gupta, H., Kling, H., Yilmaz, K., and Martinez, G.: Decomposition of the mean squared error and NSE performance criteria: implications for improving hydrological modelling, J. Hydrol., 377, 80-91, 2009.

Hay, L. E., Leavesley, G. H., Clark, M. P., Markstrom, S. L., Viger, R. J., and Umemoto, M.: Step wise, multiple objective calibration of a hydrologic model for a snowmelt dominated basin1, J. Am. Water Resour. Assoc., 42, 877-890, 2006.

Helbig, N., Löwe, H., Mayer, B., and Lehning, M.: Explicit validation of a surface shortwave radiation balance model over snowcovered complex terrain, J. Geophys. Res.-Atmos., 115, D18113, doi:10.1029/2010JD013970, 2010.

Hetrick, W., Rich, P., Barnes, F., and Weiss, S.: GIS-based solar radiation flux models, in: ACSM ASPRS Annual Convention, 3, 132-132, American Soc. Photogr. Remote Sens. + Amer. Cong. on Bethesda, Maryland, 1993.

Hofierka, J. and Suri, M.: The solar radiation model for Open source GIS: implementation and applications, Proceedings of the Open source GIS - GRASS users conference 2002 - Trento, Italy, 1113 September 2002.

Hoyt, D.: A model for the calculation of solar global insolation, Solar Energy, 21, 27-35, 1978.

Iqbal, M.: An Introduction to Solar Radiation, Academic Press, Orlando, FL, USA, 1983.

Jones, J., Keating, B., and Porter, C.: Approaches to modular model development, Agric. Sys., 70, 421-443, 2001.

Kennedy, J. and Eberhart, R.: Particle swarm optimization, in: Neural Networks, 1995. Proceedings., IEEE International Conference, volume 4, 1942-1948, 1995.

Liou, K.: An Introduction to Atmospheric Radiation, 84, Academic Press USA, 2002.

Liu, B. Y. and Jordan, R. C.: The interrelationship and characteristic distribution of direct, diffuse and total solar radiation, Solar Energy, 4, 1-19, 1960.

Long, C. N. and Ackerman, T. P.: Surface Measurements of Solar Irradiance: A Study of the Spatial Correlation between Simultaneous Measurements at Separated Sites, J. Appl. Meteorol., 34, 1039-1046, doi:10.1175/15200450(1995)034<1039:SMOSIA > 2.0.CO;2, 1995.

Miklánek, P.: The estimation of energy income in grid points over the basin using simple digital elevation model, in: Ann. Geophys., 11, European Geophysical Society, Springer, 1993.
Miller, R.: The jackknife - a review, Biometrika, 61, 1-15, 1974.

Moore, I.: SRAD: direct, diffuse, reflected short wave radiation, and the effects of topographic shading. Terrain Analysis Programs for Environmental Sciences (TAPES) Radiation Program Documentation, Center for Resource and Environmental Studies, Australia National University, Canberra, Australia, 1992.

Orgill, J. and Hollands, K.: Correlation equation for hourly diffuse radiation on a horizontal surface, Solar Energy, 19, 357-359, 1977.

Prata, A.: A new long-wave formula for estimating downward clearsky radiation at the surface, Q. J. Roy. Meteorol. Soc., 122, 1127$1151,1996$.

Quenouille, M.: Notes on bias in estimation, Biometrika, 43, 353360, 1956.

Ranzi, R. and Rosso, R.: Distributed estimation of incoming direct solar radiation over a drainage basin, J. Hydrol., 166, 461-478, 1995.

Reindl, D., Beckman, W., and Duffie, J.: Diffuse fraction correlations, Solar Energy, 45, 1-7, 1990.

Rizzoli, A., Svensson, M., Rowe, E., Donatelli, M., Muetzelfeldt, R., Wal, T., Evert, F., and Villa, F.: Modelling framework (SeamFrame) requirements, Report No. 6, SEAMLESS integrated project, EU 6th Framework Programme, contract no. 010036-2, www.SEAMLESS-IP.org, 49 pp., ISBN 90-8585-0347. 2005.

Rogers, J.: Environmental and water resources: milestones in engineering history: 15-19 May 2007, Amer. Society of Civil Engineers, Tampa, Florida, 2007.

Spencer, J.: Fourier series representation of the position of the sun, Search, 2, 172-218, 1971.

Stehr, A., Debels, P., Romero, F., and Alcayaga, H.: Hydrological modelling with SWAT under conditions of limited data availability: evaluation of results from a Chilean case study, Hydrol. Sci. J., 53, 588-601, 2008.

Tovar, J., Olmo, F., and Alados-Arboledas, L.: Local-scale variability of solar radiation in a mountainous region, J. Appl. Meteorol., 34, 2316-2328, 1995.

Van Liew, M., Arnold, J., and Bosch, D.: Problems and potential of autocalibrating a hydrologic model, Trans. ASAE, 48, 1025$1040,2005$.

Wilson, J. and Gallant, J.: Terrain Analysis: Principles and Applications, Wiley, New York, 2000. 